\title{
Diz çevresi kırıkların sirküler eksternal fiksatörler ile tedavisinin temel prensipleri
}

\section{Basic principles of treatment of knee fractures with circular external fixators}

\author{
Tolga Atay, Vecihi Kırdemir
}

Süleyman Demirel Üniversitesi Tıp Fakültesi, Ortopedi ve Travmatoloji Anabilim Dalı, Isparta

\begin{abstract}
Son on yılda artan teknolojik gelişmeye paralel olarak, kırık tespiti amacıyla cerrahların önüne birçok enstrüman sunulsa bile, bunların bir kısmı zamanla güncelliklerini kaybetmiştir. Sirküler eksternal fiksatörler ise sadece kırık tespiti değil ayrıca parçalı kırıklarda, instabil kırıklı çıkıklarda ve deformite cerrahisinde de yaygın olarak kullanılmaktadır ve popülaritesini halen hiç kaybetmemiştir. Bu derlemede, diz çevresi kırıklarında sirküler eksternal fiksatörlerin temel prensiplerinden bahsederek, genç meslektaşlarımızla bilgi ve tecrübelerimizi paylaştık.
\end{abstract}

Anahtar sözcülkler: eksternal fiksatörler; diz; kırıklar
Parallel to the increasing technological development in the last decade, even though many instruments were presented to the surgeons for the purpose of fracture fixation, some of them have lost their popularity. However, circular external fixators are not only used for fracture fixation but also for fragmented fractures, unstable dislocations and deformity surgery; they are still widely used and popular. In this section, we mentioned the basic principles of circular external fixators in the knee fractures, and shared our knowledge and experiences with our young colleagues.

Key words: external fixators; knee; fractures skiden sirküler eksternal fiksatör denildiği zaman, çoğu zaman aklımıza sadece açık kırık cerrahi tedavisi gelirdi. Günümüzde cerrahların tecrübeleri arttıkça, bunlar kısıtlı bir endikasyon alanından çıkarak, diz çevresi parçalı kırıklarda, instabil kırıklı çıkıklarda ve deformite cerrahisinde de yaygın olarak kullanılmaya başlanmıştır.

Diz çevresi kırıklarının sirküler eksternal fiksatörler ile tedavisinden bahsederken, konuyu distal femur ve proksimal tibia olarak iki ana başlığa ayıracağız.

\section{DISTAL FEMUR KIRIKLARI}

Tüm femur kırıkları içerisinde distal femur kırıkları \%3-7'lik bir kısmı kapsar. ${ }^{[1]}$ Bu tür kırıklar, gençlerde yüksek enerjili travmalar, yaşlılarda ise osteoporoza bağı düşük enerjili travmalar sonucunda oluşmaktadır. Her iki grubun da kendine göre zorlukları vardır.
Yüksek enerjili yaralanmalarda, distal femur kırığına diğer bölge kırıkları eşlik edebilir. Bunların başında örnek olarak proksimal tibia kırıkları gelir. Ayrıca, parçalı eklem içi kırıkları da görülür. Bilindiği üzere, bu tip kırıklar anatomik olarak restore edilmediği takdirde, erken yaşta osteoartrit ile karşılaşmak kaçınılmazdır. Düşük enerjili yaralanmalarda osteoporoz ön plandadır; plak-vida ile osteosentezlerde gevşeme gibi erken cerrahi komplikasyonlarla karşımıza çıkabilir. Tüm bunların ışığında, sirküler eksternal fiksatörler uygun kurallara göre yapıldığı takdirde bahsettiğimiz sorunlarla karşılaşmayız. ${ }^{1]}$

Sirküler eksternal fiksatörlerin en önemli avantajı, kırık parçaların minimal periosteal soyulma ile vaskülaritelerinin korunmasıdır. Bu şekilde cerrahi, en az düzeyde yumuşak doku hasarı ile tamamlanır. ${ }^{[2]}$ Ayrıca, distal femur kırıklarının tedavisinde, sirküler eksternal fiksatörler ile plak-vida tespiti karşılaştırıldığında,

- Illetişim adresi: Prof. Dr. Tolga Atay, Süleyman Demirel Üniversitesi Tıp Fakültesi, Ortopedi ve Travma-toloji Anabilim Dalı, Isparta Tel: 0532 - 4400099 e-posta: ataytolga@gmail.com

- Geliş tarihi: 1 Eylül 2018 Kabul tarihi: 1 Eylül 2018 
hastalara erken dönemde yüklenmeye izin verilir. Bu sayede, plak-vida sonrasında erken yüklenme ile oluşan komplikasyonlar görülmemiş olacaktır. Distal femurun parçalı eklem içi kırıklarında ise, ligamentotaksis ile kırık parçaların redüksiyonu sağlanamadığı durumlarda, minimal cerrahi insizyonla eklem içi parçaların redüksiyonu sağlanıp, az sayıda vida ve K-teli ile tespit uygulanabilir. Ardından sirküler eksternal fiksatör ile kalıcı tespit yapılır. ${ }^{[3]}$

Ilizarov sisteminin tek ve belki de en önemli dezavantajı cerrahi tecrübe gerekliliğidir. İşlem ilk başlarda, oldukça sabır gerektirir; daha sonraları ise cerrahın zor olgularda hayatını kurtaran bir işlem olarak yerini alır. Bu dezavantajı dışında, hastanın uzun süre bu cihazı taşıma zorunda olması, pin dibi enfeksiyonları ile diz eklem hareket kısıtlılığı sayılabilir. Femur proksimale yerleştirilen halkaların Schanz vidaları kuadrisepsi delip geçtiği için diz fleksiyonunu zorlaştırabilir. Bu problemi azaltabilmek amacıyla da Schanz vidasını, diz orta derecede fleksiyonda iken anteriordan değil lateralden, vastus lateralis içinden uygulamak gerekir.

Cerrahiye başlamadan önce hastanın pozisyon hazırlığı ameliyat devamı için çok önemlidir. Özellikle proksimale yerleştirilen yarım halka veya tam halkanın yerleştirilebilmesine olanak sağlaması için, hasta supin pozisyonda olmalı ve kırık taraf kalça altına yükselti yerleştirilmesi gerekir. Aynı şekilde, bu pozisyon cerrahi sırasında floroskopi kullanmamıza kolaylık sağlar. Diz altına da rulo şeklinde yükselti koyulması distal halkaların yerleştirilmesine kolaylık sağlar. Diz yaklaşık $30-45^{\circ}$ fleksiyonda olmalıdır. Bu sayede gastroknemius kası gevşeyerek kırık olan posterior femur kondillerin redüksiyonunu kolaylaştırır. Floroskopi sınırları açısından, tüm alt ekstremitenin diziliminin değerlendirilebilmesi için, ayak bileğini de içine alabilecek şekilde hasta pozisyonlanmalıdır.

Çerçeve kurulurken, distal femur kırıklarında ilk olarak en distal halka yerleştirilir. Bu ilk halka, distal femoral kondiler bölgeye kondiler blok oluşturmak amacıyla yerleştirilir. İkinci halka kırık parçaların 4-5 cm proksimaline, üçüncü halka ise $10 \mathrm{~cm}$ daha proksimale yerleştirilir. Son olarak da tespiti güçlendirmek amacıyla bir yarım halka trokanter minör seviyesine yerleştirilir. ${ }^{[4]}$

Bahsedilen çerçeve, hasta ameliyat olmadan önce 1 metre mesafeden çekilen AP röntgene göre planlanıp, önceden hazırlanıp, sterilize edilip, ameliyatta hazır bulundurulur.

Halka çapı seçilirken, hastanın karşı uyluğu örnek alınarak, halkanın iç kenarı ile cilt arasında en az
$2 \mathrm{~cm}$ mesafe kalacak şekilde seçilmelidir. Halkanın dar olması yumuşak dokuda sıkışmaya, geniş olması ise stabilite problemlerine neden olabilir. Diz eklemini geçen çerçevelerde ise, eklem seviyesine yerleştirilen menteşeler, hem erken dönemde eklem hareketi sağlar hem de eklem seviyesinde kontrollü distraksiyonla daha fazla yük vermeye izin verir ve aşırı yüklenme basıncından eklemi koruyarak stabiliteye katkı sağlar. ${ }^{[1-2]}$

Cerrahiye başlarken, önceden hazırladığımız çerçeve halkalarının daha önce bahsettiğimiz referans noktalarına uygun yerleştirilip yerleştirilmediğine bakmak amacıyla bir adet K-telini steril bantla tahmini referans noktalarına yerleştirilip, floroskopi altına kontrol etmeliyiz. Ardından steril bir kalem ile halkaları yerleştireceğimiz bölgeleri işaretlemeliyiz.

K-tellerini göndermeye, ilk olarak en distal ve en proksimal bölgeden başlamalıyız. Bu K-telleri uyluğun lateral-mediyal düzleminde ve uyluk kemiğine dik olmalıdır. Proksimal halkayı trokanterik bölgeden uyguluyorsak, burada K-teli yerine Schanz vidası kullanılmalıdır. Bu işlemi tamamladıktan sonra ise büyük kırık parçaların redüksiyonu amacıyla $2 \mathrm{~mm}$ 'lik stoplu K-telleri kullanılabilir. K-tellerinin tamamını motor yardımıyla gönderilmesi, telin kemik içindeki bölgesinde ısınmaya bağlı olarak nekroz oluşmasına ve erken gevşemesine neden olabilir. $\mathrm{Bu}$ amaçla, K-telini ilk aşamada iki korteksi geçene kadar motor desteği ile, ardından alkolle ıslatılmış spançla teli tutarak çekiçle göndermeyi tamamlamalıyız. Aynı olayın benzeri Schanz vidaları içinde geçerlidir. Schanz vidasının tamamının motor yardımıyla gönderilmesi, ikinci korkeste kırığa ve vidanın erken gevşemesine neden olur. Bunu engellemek için, önce drille her iki korteksi geçmeli, ardından Schanz vidasını T-handle ile iki korteksi geçecek şekilde göndermeliyiz.

Kullanacağımız vida ve tellerin özellikleri kemiğin yapısına göre değişmektedir. Spongiyöz kemikte trokar uçlu, kortikal kemiklerde süngü uçlu K-tellerini tercih etmeliyiz. K-telleri özellikle proksimal tibia ve distal femurda $120 \mathrm{Nw} / \mathrm{m}$ güce kadar gerilebilmektedir. Biyomekanik olarak en güçlü kombinasyon, K-telleri ile Schanz vidaların birlikte kullanılmasıdır. Anatomik yapılar göz önüne alınacak olursa, bunlar birbirlerine göre $60^{\circ}$ açıyla gönderilmeleri gerekir. Özellikle distal femur ve tibia proksimalinde, bir K-teli ve iki Schanz vidası uygulaması en güçlü tespiti sağlar. ${ }^{[1]}$

Halkaların referans noktalarına göre tespitine bakacak olursak: En proksimaldeki yani trokanter minörün altında kalacak şekilde halkamızı 

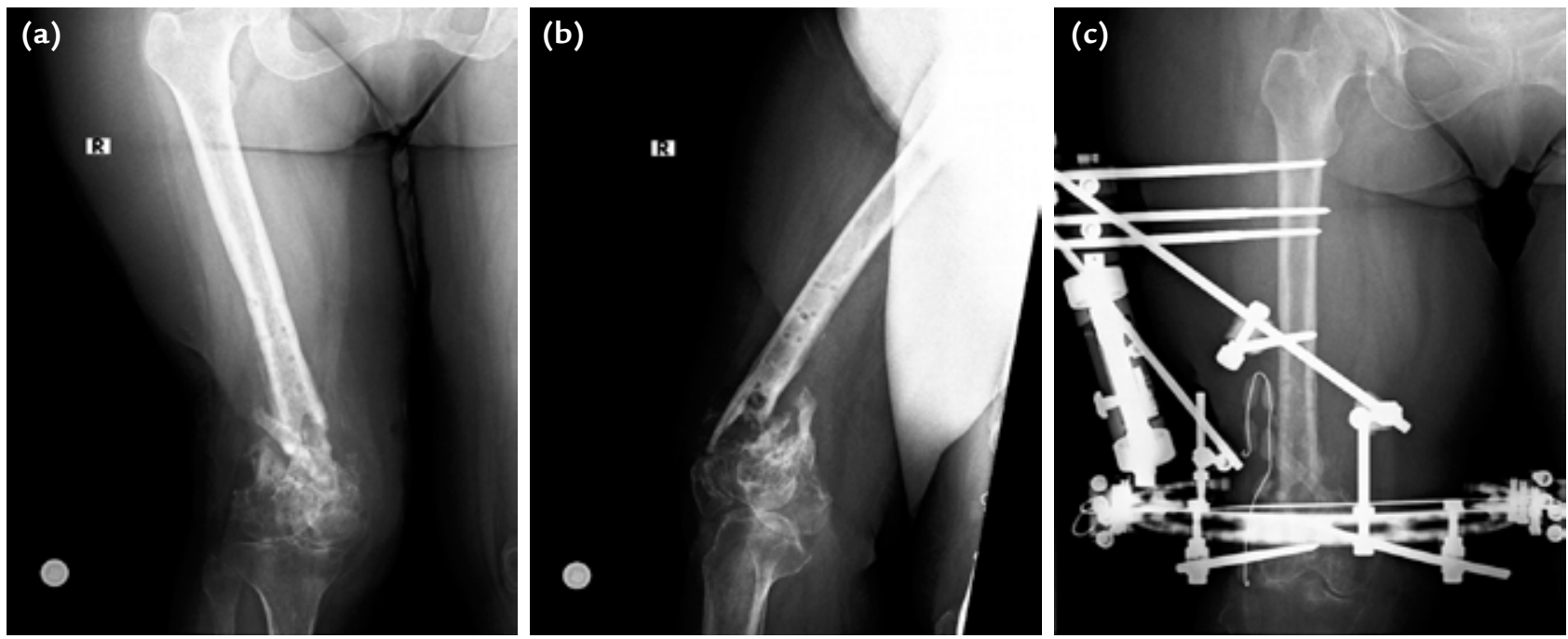

Şekil 1. a-c. Elli bir yaşında kadın hasta: distal femur enfekte; psödoartroz tanısıyla ameliyat öncesi grafisi (a, b); ameliyat sonrası 1. ay grafisi (c).

yerleştirdiğimizde, bu seviyede Schanz vidaları kullanılmalıdır. Schanz vidaları birbirlerine göre $45-60^{\circ}$ açı ile posterolateralden anteromediyale ve anterolateralden posteromediyale doğru gönderilmelidir. $\mathrm{Bu}$ aşamada geçtiğimiz kas vastus lateralistir.

Femur diyafiz kısmına yerleştirdiğimiz halka da aynı prensiple, Schanz vidaları ile tespit edilmelidir. Suprakondiler bölgedeki bir halkanın tespitinde ise istenirse lateralden mediyale, vastus lateralisten vastus mediyalise bir adet uyluğa dik K-teli gönderilebilir. Ardından Schanz vidası, posterolateralden anteromediyale veya anterolateralden posteromediyale doğru, arada en az $30^{\circ}$ olacak şekilde gönderilmelidir. Son olarak kondiler bölgede ise, K-telleri lateralden mediyale, posteromediyalden anterolaterale veya posterolateralden anteromediyale gönderilir. Tercihen, K-telleri yerine de Schanz vidaları da kullanılabilir (Şekil 1).

\section{PROKSIMAL TIBIAA KIRIKLARI}

Çoğunlukla, plato dediğimiz eklem yüzünü ve bunlara komşu olan metafizi içeren kırıklardır. illk başta bahsettiğimiz gibi, genellikle yüksek enerjili yaralanmalar sonucu meydana geldikleri için, beraberinde yumuşak doku yaralanmaları da eşlik edebilir. Bunlar içinde meniskal, ön, arka çapraz bağlar ve mediyal ile lateral kollateral bağlar olabilir. Özellikle proksimal fibula kırıkları eşlik ettiğinde fibular sinir arazları da görülebilir. ${ }^{[5]}$
Proksimal tibia kırıklarında çoğunlukla hibrid tip veya sirküler tip eksternal fiksatörler tercih edilir. Çerçevenin planlaması daha çok epifizyel bölgeye bir adet halka ve kırığın distaline yani tibianın diyafizine denk gelen kısma iki adet halka yerleştirme şeklindedir. Proksimaldeki ilk halkayı yerleştirirken, önden bir parmak arkadan ise iki parmak boşluk kalacak şekilde pozisyon verilmelidir. Halkada en az iki adet $\mathrm{K}$-teli, teller arasında ise en az $30^{\circ}$ 'lik mesafe olmalıdır. Ardından, eğer hibrid tip fiksatör kullanılacaksa, diyafize iki adet Schanz vidası kullanmak gerekmektedir. Sirküler tip eksternal fiksatör uygulanacak ise, önce ilk K-telini proksimal halkadan göndermek gerekir. Bu K-teli, posetrolateralden anteromediyale doğru, fibula başından tibiaya doğru olmalıdır. Bu esnada, diğer elimizin başparmağı fibula başının posterioruna yerleştirerek, telin fibular sinire hasar vermesi engellenir. Ardından, en distaldeki halkaya lateralden mediyale K-teli gönderilir. Böylece, floroskopi kontrolü yapıldıktan sonra kemik dizilimi sağlanır. Devamında gerekirse stoplu teller de kullanılarak, kırk redüksiyonu tamamlanır. Her halkaya stabilite açısından teller, en az iki adet ve birbirine en az $30^{\circ}$ açıda olacak şekilde, kurallarına uygun olarak gönderilir. ${ }^{[2,6]}$

Tibianın en proksimaline kullanılacak olan K-teli, eğer ekleme mümkün olduğu kadar yakın olması gerekiyorsa, subkondral kemikten en az $14 \mathrm{~mm}$ uzakta olmalıdır. Aksi takdirde septik artrit gibi komplikasyonlarla karşılaşabiliriz. ${ }^{[7]}$ 

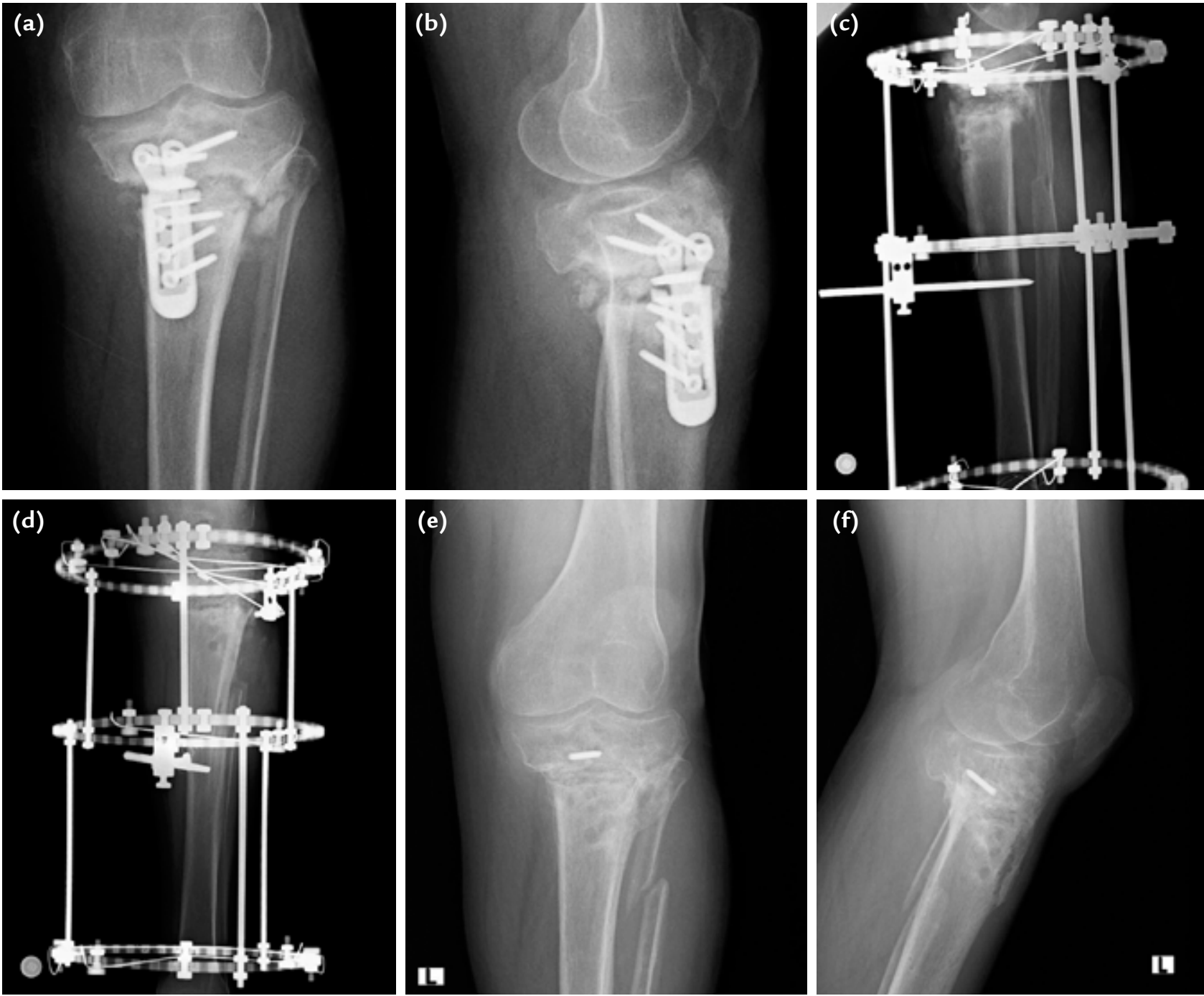

Şekil 2. a-f. Elli üç yaşında erkek hasta: proksimal tibiada psödoartroz (a, b); ameliyat sonrası sirküler eksternal fiksatör ile tespiti (c, d); ameliyat sonrası 6. ay $(e, f)$.

Sirküler eksternal fiksatörler, özellikle proksimal tibia kırıklarında eklem yüzeyini ilgilendiriyorsa, tek başlarına yeterli olmayabilir. Böyle durumlarda, mini-insizyonla eklem redüksiyonu sağlanabilir. Yardım amaçlı olarak Weber klempleri de kullanılarak, minimal osteosentezle tespit yapıldıktan sonra, sirküler eksternal fiksatör ile kırığın stabilitesi sağlanmış olur (Şekil 2). ${ }^{8,9]}$

Sirküler eksternal fiksatörler, stabilitedeki üstünlüğü, yumuşak doku koruma avantajı, gerektiğinde cerrahi sırasında çok yönlü ayarlanabilmesi ve erken yük verilebilmesi gibi özellikleriyle, çok yönlü bir tespit sistemidir. Tüm bu özelliklerinden dolayı, travma alanında, gelecekte de yerini kaybetmeyecek sistemlerden biridir.

\section{KAYNAKLAR}

1. Erdem M. Distal femur Eklem İçi Kırıklarının İlizarov Sirküler Eksternal Fiksatörle Tedavisi. İçinde: Çakmak M, Şen C, editörler. Travmada ilizarov Uygulamaları. İstanbul: Iklim Matbaa; 2013. p.120-30.

2. Tuncay I, Uzer G. Tibia Proksimal Uç Eklem İçi Kırıkları. İçinde: Çakmak M, Şen C, editör. Travmada ilizarov Uygulamaları. Istanbul: Iklim Matbaa; 2013. p.132-41.

3. Agarwal A. Open Reduction and Internal Fixation of the Distal Femur. In: Wiesel SW, editör. Operative Techniques in Orthopaedic Surgery. Philadelphia PA: Lippincott Williams \& Wilkins, 2011. p.582-603.

4. Zlowodzki M, Bhandari M, Marek DJ, Cole PA, Kregor PJ. Operative Treatment of Acute Distal Femur Fractures; Systematic Review of 2 Comparative Studies and 45 Case Series (1989 to 2005). J Orthop Trauma 2006;20(5):36671. Crossref 
5. Savolainen VT, Pajarinen J, Hirvensalo E, Lindahl J. Hybrid External Fixation in Treatment of Proximal Tibial Fractures: Agood Outcome in AO/ASIF type* C Fractures. Arch Orthop Trauma Surg 2010;130(7):897-901. Crossref

6. Ramus T, Ekholm C, Eriksson BI, Karlsson J, Nistor L. The llizarov external fixator-a useful alternative for the treatment of proximal tibial fractures: a prospective observational study of 30 consecutive patients. BMC Musculoskelet Disord 2013;14(1):11. Crossref
7. Dendrinos GK, Kontos S, Katsenis D, Dalas A. Treatment of High-Energy Tibial Plateau Fractures by the Ilizarov Circular Fixator. J Bone Joint Surg 1996;78-B(5):710-7. Crossref

8. Spiegelberg B, Parratt T, Dheerendra SK, Khan WS, Jennings R, Marsh DR. Ilizarov Principles of Deformity Correction. Ann R Coll Surg Eng 2010;92(2):101-5. Crossref

9. Marais LC, Ferreira N. Circular Eksternal Fixation in the Management of Tibial Plateau Fractures in Patients over the Age of of 55 Years. SA Orthop J 2018;17(1):35-40. Crossref 